\title{
CORRIDAS DE CAVALOS EM CAMPINAS: DAS RUAS E DOS QUI- LOMBOS AO HIPÓDROMO (1870-1898) ${ }^{1}$
}

\author{
Nara Romero Montenegro \\ Universidade Estadual de Campinas, Campinas, São Paulo, Brasil. \\ Carmen Lúcia Soares \\ Universidade Estadual de Campinas, Campinas, São Paulo, Brasil.
}

\begin{abstract}
Resumo
Este artigo analisa o surgimento e o desenvolvimento inicial das corridas de cavalos em Campinas, entre 1870 e 1898. Para analisar essa prática que expressa novas relações com a natureza, aproximamo-nos do debate acerca da historicidade dessas novas relações que se configuram em atitudes humanas diante do mundo natural. Metodologicamente, o artigo é caracterizado como pesquisa histórica, pautada pelos procedimentos da história cultural, e o conjunto de fontes foi constituído por dois jornais locais e imagens. Presentes em várias cidades brasileiras neste período, as corridas de cavalos ganham notoriedade em Campinas a partir da construção do primeiro hipódromo da cidade e atestam a passagem de uma prática de divertimento que se sistematiza e se aproxima da lógica do esporte moderno.
\end{abstract}

Palavras-chave: Corrida de cavalos. Campinas. Natureza. Turfe.

\section{Introdução}

Na segunda metade do século XIX, a corrida de cavalos era um dos mais importantes divertimentos em várias cidades brasileiras. Em Campinas, aproximadamente em 1870, já existia uma raia onde as corridas eram realizadas. Devido à sua popularidade, em 1878, é inaugurado o Hipódromo Campineiro, "fundado pela Associação do Club de Corridas Campineiro" (LAPA, 2008, p. 153).

A corrida de cavalos não representava uma transformação brusca para aquela sociedade, pois as elites locais já estavam de certo modo habituadas com a prática da montaria, sobretudo, com a chegada da Família Real Portuguesa, em 1808, que deu novo ânimo à arte da cavalaria no Brasil. Estrangeiros, como o pintor francês Jean-Baptiste Debret e os austríacos Von Martius e Johann Emanuel Pohl, narram cenas de montarias e espetáculos de cavalgadas na primeira metade do século XIX.

$\mathrm{O}$ artigo analisa o surgimento e o desenvolvimento inicial das corridas de cavalos na cidade de Campinas e esboça uma reflexão sobre a relação dessa prática com mudanças nas interações entre natureza e cidade. Embora as fontes constituídas indiquem que as corridas de cavalos eram muito populares na cidade, não encontramos, até o momento, nenhum trabalho

\footnotetext{
${ }^{1}$ Estas pesquisas tiveram financiamento da Fundação de Amparo à Pesquisa do Estado de São Paulo (FAPESP) e do Conselho Nacional de Pesquisa (CNPq).
} 
específico sobre o tema e tão somente referências esparsas em livros sobre a história de Campinas.

As fontes utilizadas neste artigo foram os jornais Gazeta de Campinas, fundado em 1869, e $O$ Diário de Campinas, fundado em 1875, bem como um conjunto de fontes iconográficas referentes ao tema.

Presente principalmente nas últimas décadas do século XIX até meados do século XX no Brasil, as corridas de cavalos ganham notoriedade em Campinas aproximadamente em 1870, com a ocorrência de alguns páreos. Anos depois, a partir da construção do primeiro hipódromo da cidade, é possível atestar a passagem de uma prática de divertimento que, progressivamente, se sistematiza e se aproxima da lógica do esporte moderno. Seria oportuno sublinhar, portanto, que as corridas de cavalos permitem pensar em uma transição conceitual em direção a essa lógica. Trata-se de uma prática que, ao se aproximar do fenômeno esportivo, sem com ele se confundir num primeiro momento, agrega distinção aos diferentes atores com ela envolvidos, tais como proprietários dos animais, espectadores e praticantes. Para Melo (2010), inclusive, é a partir do desenvolvimento do turfe que é possível falar em uma organização institucionalizada que dará ensejo ao surgimento de outras práticas esportivas na passagem do século XIX para o XX.

As corridas de cavalos no Brasil foram bastante afetadas pela lógica esportiva expressa nos seus aparatos arquitetônicos, na construção de grandes hipódromos e jockeys club, na utilização de termos como sportman ${ }^{2}$ e na realização de competições de grande repercussão popular, além da presença de gestos, regras e consumo cada vez mais universalizados. ${ }^{3}$

É muito provável que as corridas de cavalos em Campinas, no período estudado, pudessem expressar aquilo que Elias (1995) denomina de processo de esportivização. Todavia, no artigo que empreendemos, a corrida de cavalos não poderia ser considerada, na sua totalidade, como uma prática esportiva, e é desse modo que optamos por não utilizar o termo esporte, principalmente antes da construção do Hipódromo do Bonfim, no ano de 1878.

Sendo assim, atentando a possíveis deslizes, o termo esporte será evitado, preferindose utilizar simplesmente prática. Outra cautela em relação à terminologia diz respeito ao emprego do termo turfe, uma vez que as indicações de nossas fontes, principalmente dos jornais da cidade de Campinas da segunda metade do século XIX, não apontam a existência desse termo, e sim corrida de cavalos ou páreos. A escolha do emprego do termo corridas de cavalos, ao invés de turfe, e vice-versa, deve-se a uma utilização estrita do que se encontra nas fontes ou por autores que compõem nossos referenciais teóricos e nossa revisão de bibliografia.

Apesar de sua origem europeia, não seria apropriado conceber as corridas de cavalos, assim como outras práticas, de forma passiva num contexto próprio e distinto ao de sua origem, uma vez que sempre apresentam uma via de mão dupla e expressam concepções e crenças de diversas sociedades. Essa prática expressa, também, novas atitudes humanas em relação à natureza, pois surge e vincula-se ao crescimento urbano e aos novos divertimentos junto à natureza.

Tomando a historicidade das corridas de cavalos em Campinas, caberia retomar Paul Veyne, ao se referir sobre o objeto da história e suas hierarquias, quando indaga: "[...] concordaríamos em reservar o nobre nome da história a um incidente diplomático e em recusá-lo à história dos jogos e esportes? É impossível fixar uma escala de importância que não seja subjetiva[...]" (VEYNE, 1971, p.36)

\footnotetext{
2 "Denominação genérica para todos que se envolviam com o esporte, como competidores, dirigentes ou simplesmente como público aficcionado. O termo atleta ainda não era utilizado no século XIX para designar o competidor em provas esportivas" (MELO, 2007, p.147)

${ }_{3}^{3}$ Para uma discussão sobre a universalização do espírito esportivo e o questionamento a respeito da abrangência do conceito de esporte moderno, buscar Soares e Brandão (2012), "Voga esportiva e artimanhas do corpo".
} 
Destarte, consideramos o estudo da história não pertencente a uma relação de hierarquia, em que fatos diplomáticos parecem mais relevantes que formas de expressão cotidianas e mesmo corporais. Isso só foi possível com o advento da história cultural, teoria que elege novos temas, problemas, objetos e permite a constituição de uma miríade de fontes que não necessariamente se reduzem a leis e documentos oficiais.

\section{Campinas: vida urbana e novas relações com a natureza}

No final do século XIX, Campinas vive um momento de esplendor econômico resultante da densa produção de café (BARRETO, 1995, p.38), com o surgimento de uma nova elite, conhecida como Barões do Café. Impregnada dos ares aristocráticos e dos novos comportamentos e hábitos adquiridos em constantes viagens à Europa, essa elite exerceu influência sobre outras camadas da sociedade e empreendeu esforços para tornar Campinas mais próxima dos modelos de civilidade europeia.

Este é também um período em que uma forte imigração europeia se instala com a finalidade de substituir a numerosa mão de obra escrava. Esses imigrantes trazem em sua bagagem não apenas utensílios de trabalho agrícola ou industrial, mas também novos hábitos, comportamentos e maneiras de viver que poderiam ser considerados "modernos", em que se podem identificar inúmeros divertimentos, tais como as corridas de cavalos. Contudo, não seria adequado estabelecer uma relação direta e exata desta prática com a vinda desses imigrantes, pois, conforme analisa Baeninger (1996), as ondas migratórias só se efetivaram de maneira significativa na cidade de Campinas a partir de 1886, e a prática das corridas já ocorria anteriormente.

De todo modo, parece oportuno pensar que a vinda de imigrantes para Campinas, possivelmente, contribuiu para uma modernização dos costumes. Karastojanov (1999) destaca a influência desse grupo para o associativismo local, considerando o ano de "[...] 1863, na história de Campinas, como uma data intermediária, época em que a cidade começaria, logo a seguir, a se modernizar" (KARASJANOV, 1999, p.123).

Na segunda metade do século XIX, a cidade insere-se em uma nova mentalidade, consonante com a ascendência da vida urbana, cada vez mais distante do campo e acompanhando o que vinha ocorrendo em outras cidades brasileiras que atestavam, assim, grande transformação das sensibilidades.

As tensões entre importantes polos constituintes da vida cultural e política da sociedade brasileira de fins do século XIX (república-império; escravismo-abolicionismo; aristocracia-burguesia; natureza-urbanidade) encontravam-se em seu auge. Não é possível, neste período, já caracterizar a sociedade como unanimemente republicana, abolicionista, burguesa, urbana, mas sim identificar que foi ali que essas ideias se tornaram possíveis, emergiram e criaram tensões com seus respectivos opostos.

Por isso, interessante nesse momento é perceber as sutilezas desses embates e as formas que vão tomando na vida cotidiana, nas práticas e nos costumes. A aristocracia rural e a burguesia industrial, ao mesmo tempo em que disputavam poder político, dependiam-se economicamente (LAPA, 2008).

A natureza, ou melhor, ideias de natureza também transitavam por esses caminhos sinuosos e seus usos atestavam transformações, continuidades, descontinuidades. A tradição convivia com o moderno, e mais uma vez as tensões apareciam. É somente no último quartel do século XIX que Lapa (2008) identifica a acentuação de uma urbanização da natureza na cidade de Campinas, de modo que a vida urbana, aos poucos, se consolida e cria ritmos e sensibilidades próprios, inclusive acerca das ideias de natureza. Na cidade, as árvores são escolhidas com cautela e plantadas de maneira sistemática nas ruas e praças, de acordo com o que é aprazível e funcional; códigos sanitários, planejamentos urbanísticos e outros instrumentos 
não escondem o desejo de controlar a natureza de acordo com um uso considerado adequado, higiênico e estético:

Se Campinas, de resto como outras cidades, é construída a partir da paisagem natural do sítio escolhido e em estreita interação com ela, agora chegou o momento de organizar aquela paisagem, mais do que isso, de alterá-la, corrigi-la tendo em vista as carências do homem, controlá-la, quando não produzi-la, quando for o caso. (LAPA, 2008, p.127)

É nesse contexto que as corridas de cavalos surgiram como prática de divertimento vinculada a costumes mais urbanos que, sem dúvida, atestam uma clara relação de transição entre cidade e campo. A cidade, assim, torna-se não apenas o lugar de trocas econômicas, mas, também, daquelas simbólicas em que se destacam as práticas de divertimento. Ela deixa de ser o local onde se passeia nos finais de semana e, cada vez mais, essa relação se inverte, de forma que o campo passa a configurar este espaço de passeio (BADARÓ, 1996).

A urbanização das elites agrárias encontra na arquitetura um dos seus demonstradores mais eloqüentes. A transição do campo para a cidade nem sempre se faz direta, e nesse sentido, as chácaras que vão aos poucos acinturando o quadro urbano constituem um momento em que os seus moradores, beneficiados por uma acumulação que já datava de mais de meio século, procuram afastar-se do isolamento rural, sem contudo assimilar os inconvenientes urbanos, escolhendo para morada permanente as chácaras.(LAPA, 2008, p.103)

Esse conjunto de transformações que ocorria em Campinas suscitava o estabelecimento de novas relações entre a cidade e o campo. A cidade é novidade promissora financeiramente para alguns e local onde uma latente modernização se expressa em diferentes dimensões. O campo, ainda com sua grande importância econômica e simbólica, supostamente representava o lugar da pureza e da serenidade, pois, conforme escreveu Lapa, “[...] Impõe-se mudar a relação do homem com a natureza, com a cidade e com os outros homens, questionando a tradição que se apresenta com costumes e hábitos, que não mais correspondem ao que é tido como urbano e civilizado [...]" (LAPA, 2008, p.18)

Uma pressão modernizadora coexistia, entretanto, com um saudosismo em relação à vida no campo, e aspectos de ambos os lados pareciam estar assaz presentes naquela sociedade que vivia esta transição.

Melo (1999), em sua tese sobre o surgimento do turfe no Rio de Janeiro, aponta como aspectos determinantes para a emergência da prática das corridas de cavalos a influência europeia, principalmente através da chegada dos imigrantes, bem como da proximidade do cavalo na cultura da época e o firme envolvimento das elites com essa prática.

Entretanto, refletindo acerca da história de Campinas, os elementos combinados do campo e da cidade contidos tacitamente nas corridas de cavalos é que tornaram possível a sua emergência, que congrega, ao mesmo tempo, uma marca de modernização ligada a um referencial de civilização europeia e uma relação profunda com a natureza. Sua legitimação devese, assim, também a uma polarização frágil e ainda muito borrada entre vida urbana e natureza, perceptível no período estudado.

\section{As corridas de cavalos em Campinas - das ruas ao hipódromo}

As corridas de cavalos como prática moderna começam a ser organizadas no início do século XVIII na Inglaterra. ${ }^{4}$ Não se sabe exatamente quando elas chegaram ao Brasil, porém,

\footnotetext{
${ }^{4}$ No final do século XVIII e no começo do XIX, percebe-se uma maior institucionalização da prática através da fundação de jockey clubes: em 1751, na Inglaterra, e em 1833, na França. Além disso, o turfe passa a ser uma 
em 1825, já se tem registro de corridas na praia de Botafogo, no Rio de Janeiro, e, em 1849, seria criado o primeiro clube brasileiro de corridas de cavalos: o Club de Corridas, tendo como inspiração o Jockey Club francês e inglês (MELO, 1999). Em São Paulo, em 1875, foi fundado o Hipódromo pelo Club de Corridas Paulistano (FRANZINI, 2010); no Paraná, a associação Club Paranaense de Corridas foi fundada em 1873 (SILVA, 2011) e, no Rio de Grande do Sul, em 1877, foi fundado o primeiro Hipódromo de Porto Alegre (PEREIRA, 2012).

Como indicam Melo (1999) e Del Priore (2009), o cavalo já era um animal muito presente no cotidiano do século XIX e sua importância econômica e simbólica se faz presente nos jornais de Campinas, nos quais anúncios de cavalos fugidos ou furtados, com breve descrição sobre eles, são finalizados sempre com uma promessa de gratificação a quem os encontrar. Muito comum, também, é a publicidade de trajes e chapéus próprios para montaria ${ }^{5}$, inclusive para mulheres, além de crônicas, pequenas histórias ou anedotas que envolviam o animal, bem como manuais equestres.

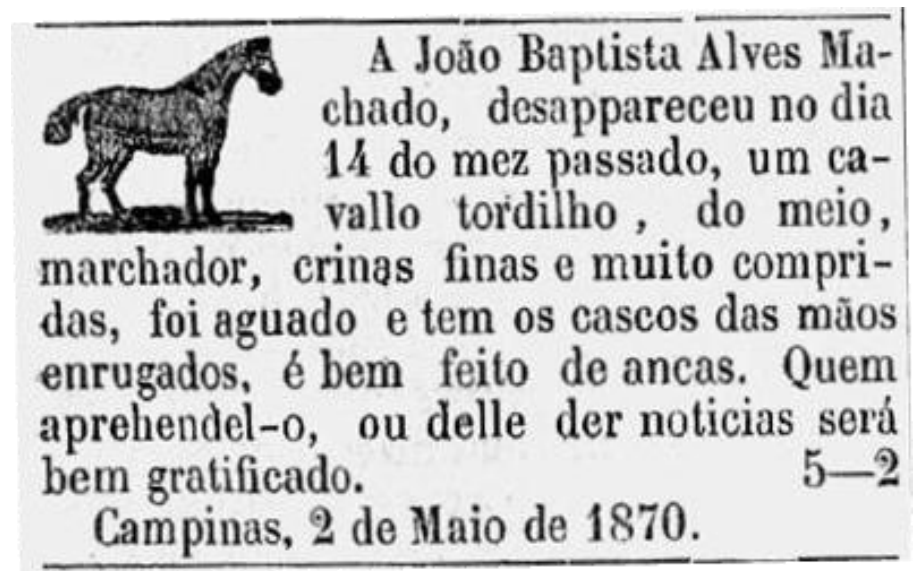

Figura 1 - Anúncio de cavalo desaparecido

Fonte: Gazeta de Campinas, 8 de maio de 1870, p.4

prática conhecida e realizada também fora da Europa, como é o caso da Austrália, tendo sua primeira corrida registrada em 1810 (BLUNT, 1977).

${ }^{5}$ Sobre roupas de montaria e equitação, Soares (2011) destaca que, além de recomendações para seus usos, havia uma necessidade, até mesmo uma exigência, entre as elites. Já no século XX, a autora destaca inclusive uma aproximação ao que chama de equidade entre os gêneros no trajar da montaria: "Homens e mulheres vestem-se sobriamente com calças compridas e paletós bem cortados, com botas que protegem as pernas e os pés, com chapéus e luvas muito semelhantes" (SOARES, 2011, p.111). 


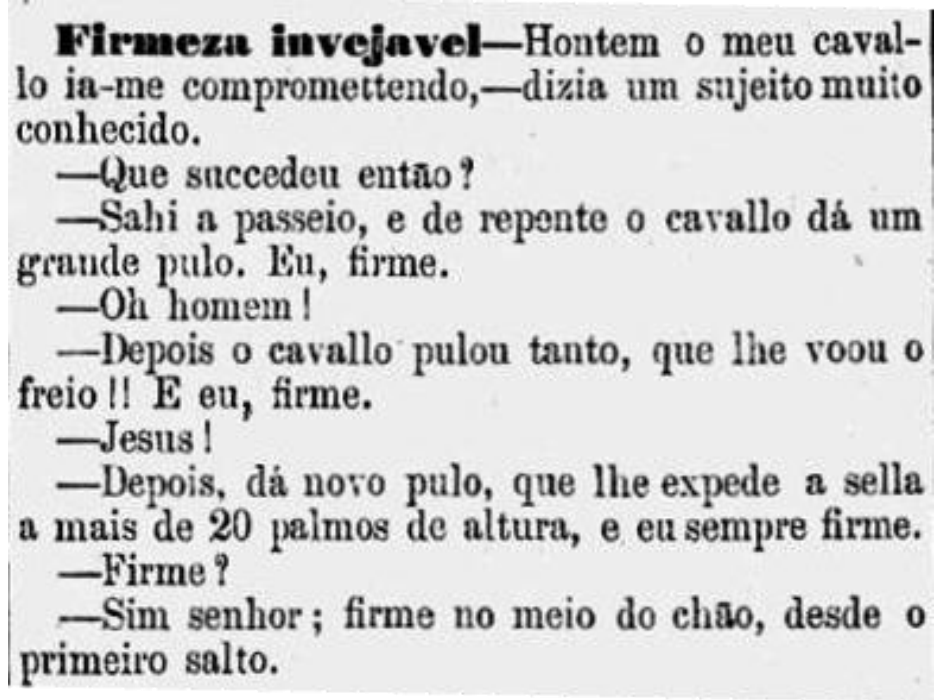

Figura 2 - Anedota

Fonte: Gazeta de Campinas, 2 de abril de 1874, p.2

Na sua primeira viagem à cidade de Campinas, em 1846, o imperador D. Pedro II prestigiou a realização de uma cavalhada ${ }^{6}$, pois, "não se comprehendia, na época, uma festa de importancia desprovida desse divertimento" (OCTAVIO, 1905, p. 9). Outras práticas de divertimento que tinham o envolvimento com o cavalo já ocorriam, como as performances circenses, nas quais os artistas realizavam distintas acrobacias montados no animal.

Inúmeras associações como clubes recreativos surgem nesse período e, no que se refere às corridas de cavalos, encontramos o Club de Corridas Campineiro, cuja inauguração teria ocorrido alguns anos antes de 1878, data da construção do Hipódromo Campineiro.

Melo (1999), Silva (2011) e Adelman e Moraes (2008) compreendem o turfe como um meio de afirmação de status pela elite que desfilava nos hipódromos com roupas distintas e tinha hábitos modernos: "Ser proprietário de um animal campeão e/ou de destaque era um importante símbolo de distinção social" (SILVA, 2011, p. 7).

Contudo, as corridas de cavalos não estavam restritas à elite (MELO, 1999); trata-se de uma prática que encena grande polissemia e diferentes níveis de participação, em que gastos e benefícios são levados em conta. Como analisa Bourdieu (2008, p.25),

Para compreender a distribuição da prática dos diferentes esportes entre as classes, seria necessário levar em consideração a representação que, em função dos esquemas de percepção e de apreciação que lhes são próprios, as diferentes classes têm gastos (de ordem econômica, cultural e "física") e benefícios associados aos diferentes esportes, benefícios "físicos" imediatos ou diferidos (saúde, beleza, força - visível com o culturalismo, ou invisível com o higienismo, etc.), benefícios econômicos e sociais.

Antes da construção do hipódromo, a prática das corridas já era comum e aparentava contar com um envolvimento popular, como indicam seus anúncios; as corridas eram realizadas em forma de parelha, isto é, dois cavalos que competiam. O jornal Gazeta de Campinas noticiou que:

Chegaram ao Quilombo, no dia 19 do corrente, os três cavallos parelheiros da Limeira, para combaterem na raia do quilombo, com os cavallos de Campinas, para re-

\footnotetext{
6 “Cavalhadas - dizem os entendidos - era o nome antigo do divertimento oriundo das justas da Meia Edade, em francez carrousel, do italiano - carrosselo, de gara - querela. Os senhores se dividiam em quadrilhas e combatiam á espada; havia depois a corrida do annel (argolinha) que era base do folguedo" (OCTAVIO, 1905, p.34-35).
} 
alisar-se as duas corridas já tratadas, tendo estas lugar nos dias 27 e 29 do corrente; sendo o primeiro: o Cavallo Preto, com o Cavallo que se apresentar no dia; e $2^{\mathrm{a}}$ corrida do Cavallo Rozilho Caipira, com o Cavallo Malla-cara do quilombo, restando só o afamado Pampa, sem carreira tratada, e por isso quem quizer chegue-se para tratar; sendo de hoje até o dia 2 de Setembro proximo. (GAZETA DE CAMPINAS, 24 ago. 1870, p.4 - grifos nossos)

A partir desse extrato, pode-se inferir que já em 1870 as parelhas eram conhecidas, como revela o adjetivo afamado para referir-se a um dos cavalos. Além disso, ao que parece, eram habituais as corridas entre cavalos de diferentes cidades, no caso Campinas e Limeira.

Mesmo sendo uma prática já bastante popular, tendo inclusive o jornal Gazeta de Campinas noticiado a presença de 3 a 4 mil espectadores em agosto de 1871, as corridas de cavalos dos primeiros anos da década de 1870 tinham regulações inusitadas: data, horário e local marcados. Isso porque, muitas vezes, pareciam acontecer sem que o público conhecesse os cavalos que iriam competir, conforme se pode ler no anúncio do dia 8 de janeiro de 1871, com o título "Corrida de cavallos: "Avisa-se aos amantes deste divertimento, que as do Pirapitanguy terão logar no dia 5 de Fevereiro proximo futuro; e quem tiver bons cavallos parelheiros e os queira fazer correr achará contentores para todas as distancias"(GAZETA DE CAMPINAS, 1871, 15 de janeiro,p.4).

Prudente notar, também, a relação com as apostas, pois são bem raras as notícias que se referem a elas ou ao termo poule $e^{7}$ antes de 1878. Mesmo com essa lacuna, é possível inferir que já eram práticas comuns dentro da realidade das corridas, pois foram daí que surgiram os primeiros argumentos a favor da institucionalização da prática. Em agosto de 1871, aparecem reivindicações efetivas tornando as corridas de cavalos mais estruturadas e regulamentadas. Nos jornais pesquisados, as corridas apareciam como injustas, devido à prática de suborno e outras trapaças. A corrupção que indigna os redatores está inserida num contexto em que as apostas eram um elemento substancial na lógica das corridas. Para organizar a prática, o dr. Joaquim Paula de Souza, presidente da Associação do Club de Corridas Campineiro, propõe a criação de um prado fechado, que faria com que "se mettam no divertimento muitos homens bons", além de "concurrencia grande e embellezamento do lugar, e melhoramento da raça cavallar" (GAZETA DE CAMPINAS, 20 ago. 1871, p.1).

O Hipódromo só foi inaugurado sete anos depois, mas, alguns dias após o comunicado de sua inauguração, um delegado de polícia publicou edital com medidas para a realização de uma corrida de grande repercussão como:

$1^{\mathrm{o}}$ Todas as pessoas que concorrerem áquelle divertimento não poderão apresentarse com armas vedadas, nos termos das leis em vigor;

$2^{\circ}$ Não poderão transitar cavalleiros pelo lado da archibancada em frente aos palanques;

$3^{\circ}$ Nenhuma pessoa que não seja dono dos cavallos, corredores, ou empregados nas carreiras, poderá transitar por meio da raia propriamente. (GAZETA DE CAMPINAS, 24 ago. 1871, p.3)

Em vários momentos, nota-se uma importante referência enaltecida da prática como originada no estrangeiro, como é o caso da manchete "Londres em Campinas", que anuncia um páreo, ou mesmo alusões explícitas de modelos de civilidade a seguir na França e na Inglaterra. Ademais, o Rio de Janeiro já se destacava como um modelo, uma vez que sua organização foi mais precoce e até mesmo as moças cariocas já frequentavam as corridas, Na Inglaterra e na França são as parelhas as festas mais concorridas. "[...] Se agora, em que vai tanta gente á tôa, a dizer brutalidades, assim mesmo vão tantas mil pessoas boas, quantas não

\footnotetext{
${ }^{7}$ Bilhetes de apostas na corrida de cavalos.
} 
irão quando fôr o Prado fechado, e poderem ir senhoras? As cariocas vão com grande enthusiasmo"(GAZETA DE CAMPINAS, 20 ago. 1871, p.1).

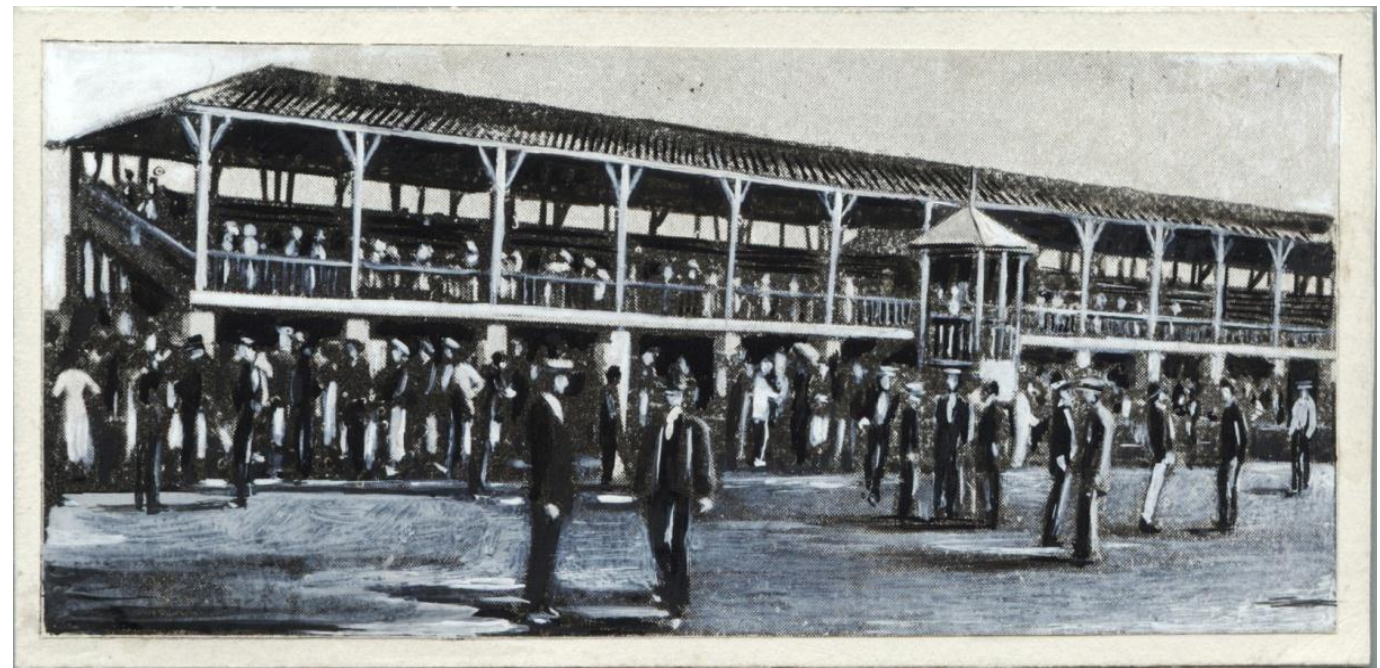

Figura 3 -Hipódromo em 1878

Fonte: Acervo Biblioteca Municipal de Campinas - MIS, s.d.

Em 4 de outubro de 1877, a Câmara Municipal de Campinas cede um terreno para a construção do Hipódromo e, aproximadamente um ano depois, em 29 de outubro de 1878, ele é inaugurado (LAPA, 2008), com entusiasmada aceitação: “[...] A uma hora em ponto, segundo o programma, começaram as corridas, diante do immenso concurso de espectadores que enchiam completamente a grande archibancada, podendo-se calcular de 5 a 6 mil pessoas presentes [...]" (GAZETA DE CAMPINAS, $1^{\circ}$ out. 1878, p.2).

Depois da construção do Hipódromo, percebe-se que os páreos são anunciados com antecedência, diferentemente do início da década de 1870. Aproximadamente, um mês antes da corrida, um primeiro programa era publicado no jornal detalhando o número e o nome dos páreos, o prêmio das apostas de cada um, os animais que poderiam competir, seus pesos, o valor da entrada e a distância da corrida. Além disso, outras informações de regulamento e inscrição apareciam no fim do anúncio, como indica o extrato a seguir apresentado pelo jornal no dia 26 de junho de 1880 :

\section{CLUB DE CORRIDAS CAMPINEIRO}

Programma da 12 corrida que terá lugar no dia 4 de Julho de 1880, terceira ordinaria do corrente anno.

Primeiro Pareo - Francisco Elizario 1:000\$000 ao primeiro; 200\$000 ao segundo, $100 \$ 000$ ao terceiro. - Distancia 1609 metros. Animaes do paiz. Entrada $100 \$ 000$.

Segundo Pareo - Premio Campineiro 2500\$000 ao primeiro; 500\$000 ao segundo, $250 \$ 000$ ao terceiro. - Distancia 3218 metros. Animaes de qualquer paiz. Entrada $250 \$ 000$.

[...] Sexto Pareo - Premio dos Pungas 200\$000 ao primeiro; $20 \$ 000$ ao segundo. Distancia 1609 metros. Animaes do paiz. Entrada 20\$000.

[...] (DIÁRIO DE CAMPINAS, 26 jun. 1880, p. 4)

Dias antes da corrida, um segundo programa com todas as inscrições realizadas era publicado. Nele repetiam-se algumas informações dos páreos, acrescidas do nome dos cavalos que iriam competir, seu pelo (Alazão, Douradilho, Zaino, etc), idade, peso, naturalidade, além da cor da roupa do jockey, nome do proprietário, entre outras informações.

Nos dias que seguiam à corrida, os resultados eram publicados com o nome do cavalo vencedor de cada páreo e, às vezes, outras informações, como o tempo da corrida do vencedor e relatos de episódios heroicos ou pitorescos. 
A dimensão que as corridas de cavalos atingiram naquele período, principalmente depois da criação do Hipódromo, vai sendo elucidada com as várias referências à prática e a toda sua organização nos jornais. O programa das corridas ocupava quase metade de uma página do jornal de apenas quatro páginas. As chamadas para as assembleias realizadas pelo Club de Corridas eram constantemente publicadas em ambos os jornais (Gazeta de Campinas e Diário de Campinas), além do anúncio da nova diretoria todo mês de janeiro. Os dias das corridas eram eventos estimados, o que talvez justifique a presença de botequins do Hyppodromo, bandas musicais e a famosa venda de poules. Em outubro de 1886, na última visita à cidade, foi registrada a presença de D. Pedro II e da imperatriz no Hipódromo Campineiro, onde foram bem recebidos, para prestigiar um páreo (LAPA, 2008).

As corridas de cavalo em Campinas aqui estudadas passaram por um profundo processo de transformação, indo das raias de ruas e dos quilombos ao hipódromo, direção que muito nos tem a dizer da sociedade campineira. A civilidade que a elite passa a exigir alcança as práticas de divertimento, operando numa lógica de classificação e de reconhecimento mútuo: "O gosto classifica aquele que procede à classificação: os sujeitos sociais distinguem-se pelas distinções que eles operam entre o belo e o feio, o distinto e o vulgar [...]" (BOURDIEU, 2008, p.13).

As classificações do que é ou deve ser apropriado no espaço da prática das corridas vão se estabelecendo de acordo com a posição ocupada por seus agentes. A crítica à maneira vulgar de praticá-la ou consumi-la, argumento importante para a realização do Hipódromo, implica comportamentos classificados por aqueles que formularam a própria classificação e são também por ela classificados como adequados.

Dois comunicados publicados na Gazeta de Campinas, em 1871, pelo dr. Joaquim de Paula Souza, que posteriormente viria a ser o presidente do Club de Corridas, trazem essa lógica da classificação. Partindo sempre da premissa de que a cidade de Campinas era muito bela e rica, parecia inaceitável seguir com as corridas tal como estavam. Do ponto de vista da legitimidade do consumo da prática, o vulgar e o distinto se exprimiam em forma de adjetivos ou contrastes entre ambos: "Haverá cousa mais triste e ridícula, do que um homem de bem agarrar-se de ditos, e ouvir grosserias e chufas de gente ordinária?" (GAZETA DE CAMPINAS, 31 ago. 1871, p.1, grifo meu); "Pensam alguns que sahindo a gente ordinaria, não irá mais ninguem. É engano e muito grande. A gente bebada e desordeira é a que affasta a boa e pacifica de ir a este divertimento, que é dos mais apreciados" (GAZETA DE CAMPINAS, 31 ago. 1871, p.1, grifo meu); "Havendo um Prado, fechado, com entrada paga, fará com que se mettam no divertimento muitos homens bons, que só procuram o prazer, e se affastem os tratantes que so procuram um meio de ganhar dinheiro desleamente" (GAZETA DE CAMPINAS, 20 ago. 1871, p.1, grifo meu). É, portanto, no encontro do vulgar (grosseria, chufas, ordinária, bêbada, desordeira, tratante) e do distinto (homem de bem, pacífica, prazer) que se exprime a posição dos sujeitos e legitima-se um tipo de manifestação da mesma prática, e não outra. 


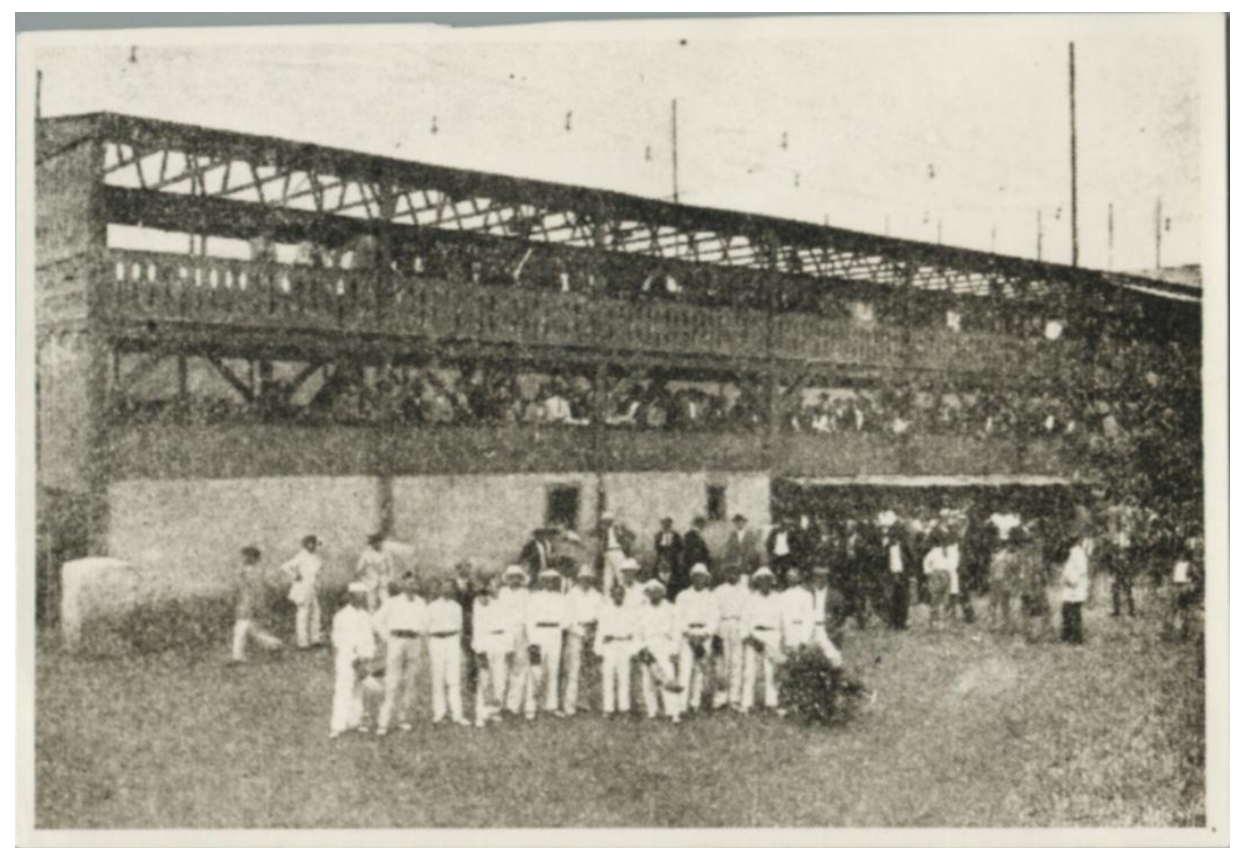

Figura 4 - Frontão Campineiro inaugurado em 18 de julho de 1897 Fonte: Acervo da Biblioteca Municipal de Campinas - MIS, s.d.

A prática da corrida de cavalos, afirmada no cenário da cidade também como espetáculo, carregava consigo várias faces de um marco de distinção. Do ponto de vista de sua realização, havia uma hierarquia na categoria dos páreos de acordo com a raça do cavalo (purosangue, meio-sangue, três-quartos-de-sangue), que possivelmente se refletia no capital econômico dos proprietários. Além disso, os jóqueis, garotos pertencentes às classes mais populares, ocupavam um lugar bastante discreto em relação ao cavalo e a seus proprietários (MELO, 1999). As poucas informações que se tem são as cores das roupas de quem iria competir no dia da corrida e raras referências a episódios atípicos que envolviam jóqueis. O capital simbólico, assim, envolvia de diferentes maneiras os agentes dessa nova forma de divertimento. Houve ainda outro argumento baseado em benefícios econômicos oriundos das corridas de cavalo que, junto à lógica de distinção relacionada à maneira legítima de consumi-la e praticála, engendraram e solidificaram uma estrutura para as corridas:

A sociedade que fizesse o Prado lucraria. Como negocio, é excellente emprego de capitaes. Supponhamos que gastasse 6 , ou menos 8 contos, que não precisava, pois não queremos luxo, só o necessário com o circulo, a archibancada, e arranjos de raia. Logo na primeira carreira, por exemplo na inauguração da estrada de ferro, teríamos no Hippodromo umas 3 a 4 mil pessoas, que a $2 \$$ dava para vencer a maioria da despeza.[...].(GAZETA DE CAMPINAS, 31 ago. 1871, p.1)

O desenvolvimento pouco conhecido dos poules possivelmente era também uma vantagem econômica encontrada por muitos. Nem mesmo a palavra poule era utilizada antes do Hipódromo Campineiro, e sim aposta. Mas já se via uma previsão do seu potencial pelos futuros organizadores:

Com o Prado, com carreiras de vários animaes, ganhando o vencendor a aposta de todos, mais o premio dado pela sociedade, o lucro seria muito superior e os incommodos actuaes desappareciam, como também as chufas e duvidas de hoje. (GAZETA DE CAMPINAS, 31 ago. 1871, p.1)

Ainda que as corridas de cavalos que se desenvolveram no final do século XIX, em Campinas, tivessem esse caráter elitista sobre o qual refletimos anteriormente, não se pode 
resumir sua estrutura como prática social exclusiva desta classe. Os interesses encontrados pelos indivíduos naquela prática (econômico, social, simbólico, etc.) variam de acordo com a classe social ou fração de classe social, sendo as expectativas, portanto, diversas (BOURDIEU, 2008).

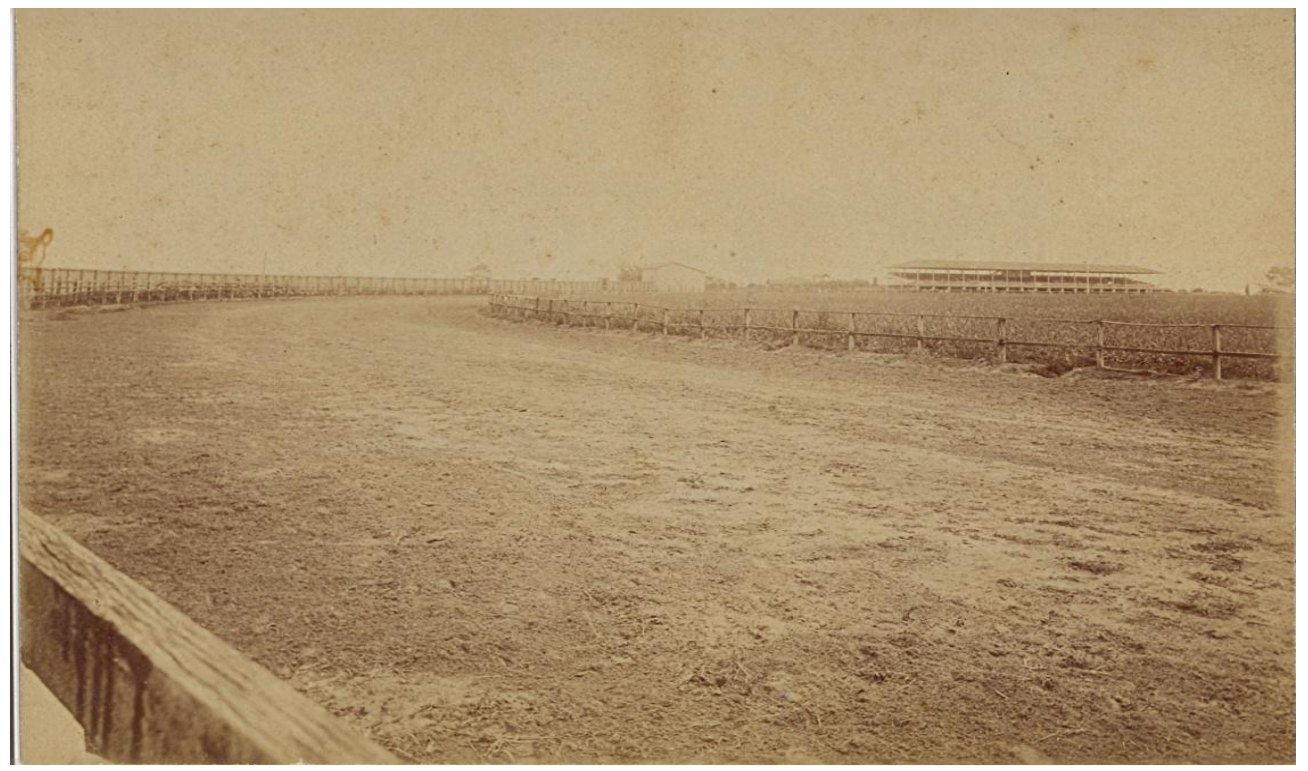

Figura 5 - Pista do Hipódromo em 1898

Fonte: Acervo Fábrica de Fumos Liberdade - MIS, s.d.

\section{Considerações finais}

O percurso aqui desenvolvido nos mostra um cenário de transformação, tanto no que diz respeito ao contexto que vivia a cidade de Campinas quanto à nova formulação das corridas de cavalos como prática de divertimento. Na segunda metade do século XIX, Campinas, cidade conhecida por seu potencial agrícola, experimentava um processo de urbanização e modernização dos costumes. Paralelamente, a corrida de cavalos, divertimento comum na época, manifestava também essas novas mudanças e necessidades de seus agentes.

A transformação pela qual passa a prática é documentada pelos jornais desde fins de 1869 a 1890, ano do fechamento do Hipódromo Campineiro devido à febre amarela. É no sentido das ruas ao hipódromo, das apostas aos poules e da espontaneidade à institucionalização que percebemos a trajetória das corridas, aliado a uma legitimidade do consumo da prática e dos costumes considerados civilizados.

Na mesma lógica é que se percebe um tratamento diferente com cavalos. É ao lado da institucionalização que, cada vez mais, há um cuidado em categorizar, treinar e até mesmo produzir um animal considerado ideal para as corridas. É o puro-sangue inglês que aparece como referência, ditando a formulação dos páreos.

As corridas de cavalos passam a ser, já no final do século XIX, grandes eventos, cuidadosamente organizados e calculados. Provavelmente expressam, mesmo que de modo tênue, uma racionalidade vanguardista, impressa a uma prática de divertimento e influente para a chegada dos esportes no século seguinte.

Por fim, concluímos refletindo acerca dos limites que este artigo comporta. As corridas de cavalos que se estruturaram, principalmente depois do Club de Corridas e do Hipódromo, não representam a totalidade da prática. Depois de 1878, os periódicos passam apenas a noticiar as corridas "oficiais", formais, organizadas pela associação. Mas nos questionamos: não estariam as corridas de cavalos envolvidas numa polissemia muito maior que as nossas 
fontes nos mostram? Improvável uma resposta para essa pergunta, entretanto, mais imprudente seria não formulá-la.

\title{
HORSE RACING IN CAMPINAS: FROM STREETS AND QUILOMBOS TO THE HIPPODROME (1870-1898)
}

\begin{abstract}
This paper analyzes the emergence and initial development of horse racing in Campinas, between 1870 and 1898. In order to analyze this practice that expresses new relations with nature, we needed to approach the debate about the historicity of these new relations that configure human attitudes towards the natural world. The paper is characterized as a historical research based on the procedures of cultural history, using a set of sources constituted by two local newspapers andimages. Horse racing was present in many Brazilian cities in this period. They gained notoriety in Campinas with the construction of the city's racecourse and confirmed the transformation of an amusement practice that is systematized towards the logics of modern sports.
\end{abstract}

Keywords: Horse racing. Campinas. Nature. Turf.

\section{CARRERAS DE CABALLOS EN CAMPINAS: DE LAS CALLES Y LOS QUILOM- BOS AL HIPÓDROMO}

\begin{abstract}
Resumen
Analizamos aquí el surgimiento y desarrollo inicial de las carreras de caballo en Campinas, entre 1870 y 1898 . Para analizar esta práctica que expresa nuevas relaciones con la naturaleza, nos aproximamos del debate sobre la historicidad de estas nuevas relaciones que se configuran en actitudes humanas frente al mundo natural. El artículo se caracteriza como una investigación histórica basada en los procedimientos de la historia cultural, y las fuentes fueron constituidas por dos diarios locales e imágenes. Presente en varias ciudades brasileras del período, las carreras de caballo ganan notoriedad en Campinas a partir de la construcción de su primer hipódromo y atestan el pasaje de una práctica de divertimento que se sistematiza y se aproxima de la lógica del deporte moderno.
\end{abstract}

Palabras-clave: Carreras de caballo. Campinas. Naturaleza. Turf.

\section{Referências}

ADELMAN, M.; MORAES, F.A. Tomando as rédeas: um estudo etnográfico da participação feminina e da/relações de gênero no turfe brasileiro. Revista Esporte e Sociedade. a.3, n.9, jul./out. 2008.

BADARÓ, R.S.C. Campinas: o despontar da modernidade. Campinas: Área de Publicações CMU/UNICAMP, 1996.

BAENINGER, R. Espaço e tempo em Campinas: migrantes e a expansão do pólo industrial paulista. Campinas: Área de Publicações CMU/UNICAMP, 1996.

BARRETTO, M. Vivendo a história de Campinas. Campinas: Mercado de Letras, 1995.

BLUNT, N. Horse racing: the inside story. London: Hamlyn, 1977. 
BOURDIEU, P. A distinção: crítica social do julgamento. São Paulo: EDUSP; Porto Alegre: ZOUK, 2008.

DEL PRIORE, M. "Jogos de cavalheiros": as atividades físicas antes da chegada do esporte. In: DEL PRIORE, M.; MELO, V.A. (Org.). História do esporte no Brasil: do Império aos dias atuais. São Paulo: Editora UNESP, 2009. p.13-33.

DIÁRIO DE CAMPINAS. [Sem título]. Campinas, 11 jun. 1876, p.4. Club de Corridas Campineiro. Campinas, 26 jun.1880, p. 4 [Sem título]. Campinas, 3 jan.1885. p.3

ELIAS, N. La génesis del deporte como problema sociológico. In: DUNNING, E.; ELIAS, N. Deporte y ocio en el proceso de la civilización. México D.F.: Fondo de cultura económica, 1995. p. 157- 184.

FRANZINI, F. Esporte, cidade e modernidade: São Paulo. In: MELO, V.A. (Org.). Os sports e as cidades brasileiras: transição dos séculos XIX e XX. Rio de Janeiro: Apicuri, 2010. p.49-70.

GAZETA DE CAMPINAS. Corridas de cavallos. Campinas, 24 ago.1870, p.4 . Corridas. Campinas, 31 ago.1871, p.1 . Corridas de cavallos. Campinas, 15 jan.1871, p.4 . As corridas. Campinas, 20 ago.1871, p.1 . Editaes. Campinas, 24 ago.1871 . [Sem título]. Campinas, 1 set.1878, p.2 . Hippodromo Campineiro. Campinas, 1 out.1878 . Sport. Campinas, 6 out. 1888, p.4 . Clube de Corridas. Campinas, 9 out.1878, p.3 Clube de Corridas. Campinas, 13 nov.1878, p.3

KARASTOJANOV, A.M.S. Vir, viver e talvez morrer em Campinas: um estudo sobre a comunidade alemã residente na zona urbana durante o Segundo Império. Campinas: Editora da UNICAMP, 1999.

LAPA, J.R.A. A cidade: Os cantos e os antros. Campinas 1860-1900. São Paulo: EDUSP, 2008. 
LAZZAROTTI FILHO, A. et al. O termo práticas corporais na literatura científica brasileira e as repercussões no campo da Educação Física. Revista Movimento, Porto Alegre, v.16, n.1, p.11-29, jan./mar.2010.

LUCENA, R. O esporte na cidade: aspectos do esforço civilizador brasileiro. Campinas: Autores Associados, 2001.

MELO, V.A. Apontamentos para uma história comparada do esporte: um modelo heurístico. Revista Brasileira de Educação Física e Esporte, São Paulo, v.24, n.1, p.107-20, jan./mar. 2010

MELO, V.A. Cidade "sportiva": o turfe e o remo no Rio de Janeiro (1849 - 1903). 1999. Tese (Doutorado em Educação Física) - Programa de Pós-Graduação em Educação Física da Universidade Gama Filho, Rio de Janeiro, 1999.

Dicionário do esporte no Brasil: do século XIX ao início do século XX. Campinas, SP: Autores Associados, 2007.

OCTAVIO, B. Campinas antiga: as festas de 1846. Campinas: Typ a vap; Livro Azul, 1905. PEREIRA, E.L. As práticas equestres em Porto Alegre: percorrendo o processo da esportivização. 2012. Dissertação (Mestrado em Educação Física) - Programa de Pós-Graduação em Ciências do Movimento Humano, Universidade Federal do Rio Grande do Sul, Porto Alegre, 2012.

SEVCENKO, N. Orfeu extático na metrópole: São Paulo, sociedade e cultura nos frementes anos 20. São Paulo: Companhia das Letras, 1992.

SILVA, M.M. Novos modos de olhar: outras maneiras de se comportar: a emergência do dispositivo esportivo da cidade de Curitiba. 2011. Tese (Doutorado em Educação) - Programa de Pós-Graduação em Educação na Universidade Estadual de Campinas, Campinas, 2011.

SOARES, C.L. As roupas nas práticas corporais e esportivas: a educação do corpo entre o conforto, a elegância e a eficiência (1920-1940). Campinas-SP: Autores Associados, 2011.

SOARES, C.L.; BRANDÃO L. Voga esportiva e artimanhas do corpo. Revista Movimento, Porto Alegre, v. 18, n.3, p. 11-26, jul./set. de 2012.

THOMAS, K. O homem e o mundo natural: mudanças de atitude em relação às plantas e aos animais. São Paulo: Companhia das Letras, 1988.

VEYNE, P.M. Como se escreve a história. Brasília: Editora Universidade de Brasília, 1971.

Recebido em: 09/06/2017

Revisado em: 28/07/2017

Aprovado em: 10/08/2017

Endereço para correspondência:

nararomerom@ hotmail.com

Nara Romero Montenegro

Universidade Estadual de Campinas 
Cidade Universitária Zeferino Vaz - Barão Geraldo,

Campinas - SP, 13083-970 